\title{
Peran Gender Sebagai Group Pada Kepemimpinan Path Goal Dan Motivasi Sebagai Determinan Kinerja Guru
}

\author{
Ni Made Satya Utami ${ }^{(1)}$ \\ I Made Purba Astakoni(2) \\ ${ }^{(1)}$ Prodi Manajemen Fak Ekonomi dan Bisnis Univ Mahasaraswati Denpasar

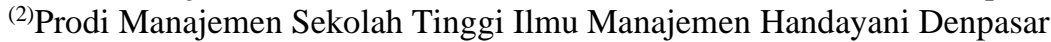 \\ e-mail: satyakesawa@unmas.ac.id
}

\begin{tabular}{|l|l|l|}
\hline Diterima: 21 Desember 2019 & Direvisi: 21 Januari 2020 & Disetujui: 27 Januari 2020 \\
\hline
\end{tabular}

\begin{abstract}
The objectives of this study are: 1) analyzing and explaining the influence of leadership on the path-goal model on teacher performance, 2) analyzing and explaining the effect of work motivation on teacher performance, 3) testing the role of gender as a group in the teacher performance determination model. The population in this study is 43 public elementary schools in Denpasar, Kota Denpasar. Samples were taken as many as 4 elementary schools which are expected to represent the population with 80 respondents interviewed by teachers and education personnel. The analysis technique uses the Partial Least Square (PLS) approach. Based on the analysis results it can be explained that; the first hypothesis testing results obtained that the path-goal leadership has a positive effect on teacher performance, with a coefficient of 0.097 and a $t$-statistic of 0.364 ( $t$-statistic $0.364<1.96)$ or a p-value of $0.176(>0.05)$, meaning a hypothesis 1 is not acceptable. In testing the second hypothesis, it is found that work motivation has a positive effect on teacher performance with a coefficient value of 0.099 and a p-statistic of 0.340 (p-statistics of $0.340<1.96$ ) or a p-value of 0.734 (> 0.05), that means the hypothesis 2 is not acceptable. The role of women's gender through the construct of leadership to teacher performance is greater than male gender. While male gender through the construct of motivation towards teacher performance is greater than female gender.
\end{abstract}

Keywords; Teacher Performance, Work Motivation, Path-Goal Model Leadership, Gender.

\section{Pendahuluan}

Banyak faktor yang bisa diangkat sebagai penentu kinerja organisasi diantaranya Khoir (2012) menyebutkan terdapat 11 faktor yang bisa diangkat yaitu; motivasi, kepemimpinan, budaya organisasi, kemampuan pegawai, kompensasi, kompetensi, iklim organisasi, disiplin kerja, pengembangan karir, sumberdaya yang ada, spiritual. Menurut Mulyasa $(2005 ; 140)$ faktor-faktor yang mempengaruhi kinerja seorang guru antara lain: 1) Sikap mental berupa motivasi, disiplin dan etika kerja; 2) Tingkat pendidikan; 3) Manajemen atau gaya kepemimpinan kepala sekolah dan bubungan industrial; 4) Tingkat penghasilan atau gaji yang memadai; 5).Kesehatan; 6) Jaminan sosial; 7) Kualitas sarana pembelajaran; 8) Teknologi; 9). Kesempatan berprestasi. Guru merupakan salah satu komponen penting demi keberhasilan pendidikan, karena peran guru sangat vital dalam upaya meningkatkan kualitas pendidikan secara umum. 
Berdasarkan observasi awal yang dilakukan di beberapa Sekolah Dasar Negeri Denpasar Barat Kota Denpasar, bisa dijelaskan bahwa dari sisi gender, jumlah perempuan sebanyak 65,00\% dan laki-laki 35\%).Dari data tersebut menunjukkan bahwa jumlah guru perempuan lebih banyak dibandingkan dengan guru laki-laki, namun pada posisi sebagai pengambil keputusan (Kepala Sekolah) semua didominasi oleh guru laki-laki. Data dan fakta tersebut menunjukkan bahwa jumlah guru perempuan lebih banyak ternyata tidak menjamin posisi, kedudukan, status dan peran perempuan seimbang atau sama dengan laki laki. Membicarakan persoalan gender berarti membahas persoalan relasi sosial antara perempuan dan laki-laki yang dipertautkan dengan pembagian kerja dan tanggungjawab, serta bagaimana cara relasi itu dibangun dan dikonstruksikan secara sosial dan budaya oleh masyarakat (Hatifah, 2015). Dalam studi kali ini secara sederhana ingin dilihat peran gender secara terpisah dalam mempengaruhi kinerja guru melalui kepemimpinan dan motivasi kerja.

Kepala sekolah harus mampu menjalankan fungsinya dalam menciptakan dan memelihara suasana pekerjaan yang sehat dan menyenangkan serta menjalankan fungsinya agar dapat mencapai tujuan organisasi (Indrafachrudi 2006;3). Mulyasa (2004;97) menyatakan bahwa peran dan fungsi yang harus dilaksanakan oleh kepala sekolah sebagai seorang pemimpin diantaranya sebagai edukator, manajer, administrator, supervisor, leader, inovator dan motivator. Jika peran dan fungsi ini diperhatikan dengan baik maka akan memberikan hal yang positif dalam peningkatan semangat kerja guru. Beberapa temuan penelitian tentang kepemimpinan kepala sekolah seperti Ngiode (2016) , Triwahyuni, Thamrin, and Widodo (2014) mendapatkan pengaruh yang positif signifikan antara kepemimpinan kepala sekolah dengan kinerja guru. Berbeda dengan hasil riset dari Sampurno \& Wibowo (2017) bahwa motivasi kerja tidak berpengaruh terhadap kinerja guru dan tenaga kependidikan.

Motivasi kerja tidak lain dari suatu yang menimbulkan dorongan atau semangat kerja. Motivasi didefinisikan sebagai kekuatan pendorong yang memaksa seseorang untuk mengambil beberapa tindakan untuk mencapai tujuan tertentu (Inayatullah and Jehangir 2012). Motivasi kerja merupakan suatu modal dalam menggerakkan dan mengarahkan para karyawan atau pekerja agar dapat melaksanakan tugasnya masing-masing dalam mencapai sasaran dengan penuh kesadaran, kegairahan dan bertanggung jawab (Hasibuan 2007;141). Hal ini menunjukan bahwa kepemimpinan kepala sekolah dapat memberikan pengaruh terhadap besar kecilnya motivasi kerja guru. Beberapa hasil riset yang mengkaitkan antara motivasi kerja dengan kinerja guru seperti Mustafa and Othman (2010), Sulistyawati, Fasochah, and Darsono (2016), Ngiode (2016), Yunidar (2015) Djafar and Nurhafizah (2018), Abast et al. (2018), menjelaskan bahwa terdapat pengaruh positif signifikan antara motivasi kerja dengan kinerja guru. Berbeda dengan hasil riset dari Sampurno and Wibowo (2017) bahwa motivasi kerja tidak berpengaruh terhadap kinerja guru dan tenaga kependidikan.

Berdasarkan latar belakang di atas maka kepemimpinan model path goal dan motivasi kerja merupakan faktor yang diduga sebagai penentu kinerja guru dan diperkuat dengan hasil 
penelitian sebelumnya maka perlu diangkat suatu studi maka studi ini bertujuan untuk mengungkap pengaruh variabel eksogen kepemimpinan model path goal dan motivasi kerja, terhadap variabel endogen yaitu kinerja guru serta menguji peran gender baik laki dan perempuan terhadap kinerja guru

\section{Telaah Literatur dan Kajian Pustaka}

\section{Kinerja}

Kinerja adalah penyelesaian tugas yang disepakati dari pemberi kerja dan hasil yang didapatkan sesuai fungsi atau aktivitas pekerjaan tersebut selama waktu tertentu ( Robbins 2008:28). Sedangkan pandangan lain kinerja itu adalah nilai dari setiap perilaku karyawan yang berkontribusi, baik secara positif ataupun negatif untuk pencapaian tujuan organisasi (Cokquitt and LePine 2009:11). Robbins and Judge (2009:57) mengatakan kinerja ditentukan oleh tiga faktor: 1) kinerja merupakan tugas, 2) perilaku kewarganegaraan, dan 3) perilaku kontra-produktif. Jadi kinerja adalah fungsi dari kemampuan karyawan, penerimaan tujuan, tingkat tujuan, dan interaksi tujuan dengan kemampuan mereka. Konstruk kinerja guru secara operasional dapat diukur dengan menggunakan 5 (lima) indikator Susanto (2012) yaitu ; 1) Guru harus bisa menunjukkan kualitas hasil kerja; 2) Guru mampu tepat waktu dalam menyelesaikan pekerjaan, 3) Guru memiliki inisiatif/prakarsa dalam menyelesaikan pekerjaan,4) Guru memiliki kemampuan menyelesaikan pekerjaan, 5) Guru bisa berkomunikasi/kemampuan membina kerjasama dengan pihak lain.

\section{Model Kepemimpinan Path-Goal}

Kepemimpinan adalah kemampuan untuk mempengaruhi orang untuk bersedia mengikuti bimbingan seseorang atau mematuhi keputusan seseorang dan proses mempengaruhi anggota organisasi untuk menggunakan energi mereka secara sukarela dan tepat waktu untuk memfasilitasi pencapaian tujuan organisasi (Timpe 2002:45). Ketika diterapkan ke sekolah, kepala sekolah adalah pemimpin organisasi sekolah yang posisinya sah sebagai manajer sekolah, pembawa posisi memainkan peran profesionalisme memimpin sekolah untuk mengambil tindakan guna mempengaruhi dan memperkuat guru dan staf dalam upaya bersama untuk mencapai tujuan pendidikan. Kepemimpinan model path-goal ini cukup terkenal serta model ini didasarkan pada teori expectancy, Model path-goal menjelaskan bagaimana seorang pemimpin dapat memudahkan bawahan melaksanakan tugas dengan menunjukkan bagaimana prestasi mereka dapat digunakan sebagai alat untuk mencapai reward yang diinginkan. Teori expectancy menjelaskan bagaimana perilaku individu dipengaruhi oleh hubungan antara usaha dan prestasi (path-goal) dengan valensi dari reward (goal attractive-ness), maka individu akan memperoleh kepuasan dan produktif ketika melihat hubungan yang kuat antara usaha dan prestasi mereka dan ketika hasil prestasi mereka atas reward dengan nilai tinggi. Model path-goal mengklaim bahwa pemimpin yang paling efektif adalah mereka yang membantu bawahan mengikuti alur untuk mencapai reward yang bernilai. Model path-goal menganjurkan bahwa kepemimpinan terdiri dari dua fiungsi dasar. Pertama adalah memberi kejelasan alur pemimpin membantu bawahan dalam memahami perilaku bagaimana yang 
diperlukan didalam menyelesaikan tugas. Kedua adalah meningkatkan jumlah dari reward yang disediakan untuk bawahan dengan memberi dukungan dan perhatian terhadap kebutuhan pribadi mereka, untuk membentuk fungsi-fungsi tersebut pemimpin dapat mengambil berbagai gaya kepemimpinan, empat perbedaan gaya kepemimpinan dijelaskan dalam model berikut (Ma'Ruf 2014):(1) Diretive leadership: memberitahukan kepada bawahan apa yang diharapkan dari mereka yang memberi guidance secara spesifik, standar-standar, dan jadwal kerja.(2) Supportive leadership: memperlakukan bawahan sama dan menunjukkan tentang keberadaan mereka, status, dan kebutuhan- kebutuhan pribadi sebagai usaha untuk mengembangkan hubungan interpersonal yang menyenangkan di antara anggota kelompok.(3) Participative leadership; selalu meminta/ melibatkan pertimbangan bawahan dan menggunakan saran, masukan dan ide mereka didalam pengambilan keputusan.(4) Achievement-oriented leadership; menentukan sasaran-sasaran yang akan dicapai, mengharapkan bawahan untuk berprestasi pada level yang paling tinggi, dan secara terus menerus mencari pengembangan prestasi diri.

\section{Motivasi}

Motivasi didefinisikan sebagai kekuatan pendorong yang memaksa seseorang untuk mengambil beberapa tindakan untuk mencapai tujuan tertentu. Tingkat motivasi setiap orang juga berbeda seperti halnya persepsi, juga sikap setiap orang berbeda. Lebih lanjut Mangkunegara (2010;94) mengatakan bahwa motivasi kerja didefinisikan sebagai kondisi yang mempengaruhi gairah, arah, dan pemeliharaan perilaku yang relevan dalam pengaturan kerja. Mulyasa (2005: 145) mengemukakan motivasi adalah daya penggerak yang telah aktif, yang terjadi pada saat tertentu, terutama bila kebutuhan untuk mencapai kebutuhan sempat dirasakan atau mendesak. Sedangkan menurut Robbins (2008: 208) motivasi adalah kesediaan untuk mengeluarkan tingkat upaya yang tinggi untuk tujuan organisasi, yang dikondisikan oleh kemampuan upaya didalam memenuhi kebutuhan individual. Pengukuran motivasi kerja mengacu pada lima jenjang kebutuhan (Robbins 2008;86), (Astakoni 2015), sehingga indikatornya menjadi, (1) Kebutuhan Fisiologis: antara lain rasa lapar, haus, perlindungan (pakaian dan perumahan), seks, dan kebutuhan jasmani lain; (2) Kebutuhan keamanan: antara lain keselamatan dan perlindungan terhadap kerugian fisik dan emosional;(3) Kebutuhan sosial: mencakup kasih sayang, rasa memiliki, diterima baik, dan persahabatan;(4) Kebutuhan akan penghargaan: mencakup faktor penghormatan diri seperti harga diri, otonomi, dan prestasi; serta faktor penghormatan dari luar seperti misalnya status, pengakuan, dan perhatian;(5) Kebutuhan aktualisasi diri: dorongan untuk menjadi seseorang/sesuatu sesuai ambisinya yang mencakup pertumbuhan, pencapaian potensi, dan pemenuhan kebutuhan diri.

\section{Pengaruh Kepemimpinan Path Goal Terhadap Kinerja Guru}

Menurut (Pidarta 2004;2) mengemukakan ada beberapa faktor yang dapat mempengaruhi kinerja guru dalam melaksanakan . Kepemimpinan kepala sekolah merupakan kemampuan kepala sekolah untuk menggerakkan, mengerahkan, membimbing, melindungi, memberi 
teladan, memberi dorongan, dan memberi bantuan terhadap sumber daya manusia yang ada di suatu sekolah sehingga dapat didayagunakan secara maksimal untuk mencapai tujuan yang telah ditetapkan .Dalam paradigma baru manajemen pendidikan, seorang kepala sekolah harus melakukan peranannya sebagai pimpinan dengan menjalankan fungsi sebagai educator, manager, administrator, supervisor, leader, innovator dan motivator (Mulyasa, 2004;98). Beberapa temuan penelitian tentang kepemimpinan kepala sekolah didapat oleh (Rasool et al. 2015) yang menemukan bahwa kepemimpinan transformasi berpengaruh positif kuat terhadap kinerja pegawai. Temuan yang didapat oleh Rachmawati (2013), Septiana, Ngadiman, and Ivada (2013),Arifin et al. (2014), Manik and Bustomi (2011) , Ngiode (2016), Purwoko (2018), Triwahyuni, Thamrin, and Widodo (2014) yang mendapatkan terdapat pengaruh yang positif signifikan antara kepemimpinan kepala sekolah dengan kinerja guru. Berdasarkan uraian diatas maka dalam studi ini diangkat hipotesis $\mathrm{H}_{1}$;K e pe mimpinan model path goal kepala sekolah berpengaruh signifikan positif terhadap kinerja guru.

\section{Pengaruh Motivasi Kerja Terhadap Kinerja Guru}

Menurut Robbins ( 2008:18 ) motivasi kerja merupakan suatu proses yang menghasilkan suatu intensitas, arah dan ketekunan individual dalam usaha untuk mencapai tujuan. Apabila dikaitkan dengan tugas pekerjan, motivasi kerja mempunyai peranan penting dalam organisasi karena menyangkut manusia dalam organisasi. Motivasi adalah serangkaian sikap dan nilai yang mempengaruhi individu untuk mencapai hal yang spesifik sesuai dengan tujuan individu. Sikap dan nilai tersebut merupakan suatu yang invisible yang memberikan kekuatan untuk mendorong individu bertingkah laku dalam mencapai tujuan. Beberapa hasil penelitian seperti Mustafa and Othman (2010),Zulkifli, Darmawan, and Sutrisno (2014),Sulistyawati, Fasochah, and Darsono (2016), Ngiode (2016), Yunidar (2015),Djafar and Nurhafizah, 2018), Abast et al. (2018), menjelaskan bahwa terdapat pengaruh positif signifikan antara motivasi kerja dengan kinerja guru. Berbeda dengan temuan dari Sampurno and Wibowo (2017) bahwa motivasi kerja tidak berpengaruh terhadap kinerja guru dan tenaga kependidikan. Berdasarkan studi sebelumnya maka diangkat hipotesis sebagai berikut; $\mathrm{H} 2$; Motivasi kerjaberpengaruh signifikan positif terhadap kinerja guru.

\section{Metode Penelitian}

Populasi dalam penelitian ini adalah seluruh Sekolah Dasar (SD) Negeri yang ada di Denpasar Barat Kota Denpasar (pada tahun 2018) sebanyak 43 Sekolah Dasar (SD) Negeri. Dari keempat SD sampel yang diangkat berdasarkan hasil observasi lapangan, jumlah seluruh Guru dan tenaga kependidikan adalah 80 orang, sehingga seluruhnya akan dijadikan responden dalam penelitian ini. Penelitian ini menggunakan teknik pengumpulan data melalui wawancara, dengan terlebih dahulu menyiapkan kuesioner.

\section{Definisi Operasional Variabel}

Kinerja Guru 
Dessler (2005:35) menyatakan bahwa kinerja merupakan hasil kerja yang dapat dicapai oleh seseorang atau sekelompok orang dalam suatu organisasi, sesuai dengan wewenang dan tanggung jawab masing-masing, dalam upaya untuk mencapai tujuan organisasi yang bersangkutan. Variabel kinerja guru dan tenaga kependidikan secara operasional diukur dengan menggunakan 5 (lima) indikator (Susanto 2012) yaitu ; 1) Guru harus bisa menunjukkan kualitas hasil kerja; 2) Guru mampu tepat waktu dalam menyelesaikan pekerjaan, 3) Guru memiliki inisiatif dalam menyelesaikan pekerjaan,4) Guru memiliki kemampuan menyelesaikan pekerjaan, 5) Guru bisa berkomunikasi dan membina kerjasama dengan pihak lain.

Kepemimpinan Model Path Goal

Menurut (Timpe 2002:33) kepemimpinan adalah kemampuan untuk mempengaruhi orang untuk bersedia mengikuti bimbingan seseorang atau mematuhi keputusan seseorang dan proses mempengaruhi anggota organisasi untuk menggunakan energi mereka secara sukarela dan tepat waktu untuk memfasilitasi pencapaian tujuan organisasi. Indikator yang digunakan mengacu pada House and Mitchell (1975:55) ,Ma'Ruf (2014) yaitu ; 1) Kepemimpinan pengarah (directive leadership);2) Kepemimpinan pendukung (supportive leadership);3) Kepemimpinan partisipatif (participative leadership); 4) Kepemimpinan berorientasi prestasi (achievement-oriented leadership)

Motivasi Kerja

Motivasi kerja adalah kondisi yang berpengaruh membangkitkan, mengarahkan dan memelihara perilaku yang berhubungan dengan lingkungan kerja (Mangkunegara 2010;94). Indikator motivasi kerja mengacu pada lima jenjang kebutuhan (Robbins 2008;96), (Astakoni 2015) ; (1) Kebutuhan Fisiologis; (2) Kebutuhan Keamanan;(3) Kebutuhan Sosial: (4) Kebutuhan akan penghargaan;(5) Kebutuhan aktualisasi diri

\section{Teknik Analisis Data}

Analisis Statistik Deskriptif dan Analisis Statistik Inferensial. Melalui analisis statistik inferensial dalam penelitian ini menggunakan pendekatan Partial Least Square (PLS). Dalam PLS path modeling terdapat dua model yaitu outler model dan inner model.

\section{Hasil Penelitian dan Pembahasan}

Deskripsi Karateristik Responden

Berdasarkan jumlah sampel yang ada, maka karateristik responden sebagai berikut: Dari sisi gender, jumlah perempuan sebanyak 52 orang atau 65,00 \% dan laki-laki 28 orang (atau $35 \%$ ).Dari sisi usia/umur, pada interval umur > 55 tahun sebanyak 20\%, umur 46-55 tahun sebesar $18,80 \%$, umur 36-45 tahun 10\%, umur 26-35 tahun sebesar 33,80\%, umur 18-25 tahun 17,50\%. Dari sisi lama kerja/masa kerja , antara 1 - 5 tahun sebanyak 38,80\%, masa kerja 6-10 tahun sebanyak $30,00 \%$, masa kerja > 21 tahun sebanyak 26,30\%, sisanya dengan masa kerja 15-20 tahun sebanyak 5\%.Dari sisi tingkat pendidikan terakhir, responden berpendidikan (S1 atau S2) sebanyak 91,30\%, walau pada sisi lain masih ada yang berpendidikan SD sebesar 2,50\%. Dari sisi besarnya perkiraan 
pendapatan pada interval 5-10 juta sebanyak 27,50\%, antara 3- 5 juta sebanyak 32,50\% dan sisanya dengan tingkat pendapatan $<3$ juta sebanyak $40 \%$.

Evaluasi Outler Model

Pada pengujian outler model, dilakukan melalui 2 kali iterasi. Pada iterasi pertama indikator kinerja perlu dihilangkan karena memiliki koefsien $0,37<0,50$. Pada iterasi kedua (final), dengan menghilangkan indikator, teramati bahwa semua koefisien memenuhi syarat untuk analisis lebih lanjut.Convergent Validity dari measurement model dengan indikator reflektif dapat dilihat dari korelasi antar skor indicator dengan skor konstruknya (variabel laten). Indikator individu dianggap valid jika memiliki nilai outler loading diatas $(>0,50)$.Oleh karena seluruh indikator yang merefleksikan masing-masing konstruk memiliki nilai outer loading> 0,50 dan signifikan pada level 0,05 maka seluruh indikator adalah valid.Pengukuran validitas indikator-indikator yang membentuk variabel laten, dapat pula dilakukan melalui discriminant validity. Hasil perhitungan menunjukkan bahwa nilai AVE seluruh konstruk > 0,50, dan rata-rata seluruh nilai Akar AVE lebih besar dari korelasi antar konstruk, sehingga memenuhi syarat valid berdasarkan criteria discriminant validity. Suatu pengukuran dapat dikatakan reliabel, apabila composite reliability dan cronbach alpha memiliki nilai lebih besar dari 0,70. Composite reliability dan Cronbach alpha adalah merupakan suatu pengukuran reliabilitas antar blok indikator dalam model penelitian.Nilai composite reliability dan Cronbach Alpha seluruh konstruk telah menunjukkan nilai lebih besar dari 0.70, sehingga memenuhi syarat reliable berdasarkan criteria composite reliability.

Evaluasi Inner Model

Uji Inner Model dipergunakan untuk mengevaluasi hubungan antar konstruk laten seperti yang telah dihipotesiskan dalam penelitian. Hasil pengujian model struktural dimana hasil yang diharapkan adalah Ho ditolak atau nilai sig < 0,05 (atau nilai t statistic $>1,96$ untuk uji dengan level of signifikan $5 \%)$.

Tabel 1: Path Analysis dan Pengujian Hipotesis

\begin{tabular}{lcccccc}
\hline \multicolumn{1}{c}{ Path Analysis } & $\begin{array}{c}\text { Original } \\
\text { Sample (O) }\end{array}$ & $\begin{array}{c}\text { Sample } \\
\text { Mean (M) }\end{array}$ & $\begin{array}{c}\text { Standard Error } \\
\text { (STERR) }\end{array}$ & \multicolumn{2}{c}{$\begin{array}{c}\text { T Statistics P-Value } \\
\text { (O/STERR) }\end{array}$} & Keterangan \\
\hline Kepemimpinan Path-Goal $\rightarrow$ Kinerja Guru & 0,097 & 0,115 & 0,265 & 0,364 & 0,716 & $\begin{array}{c}\text { Tidak } \\
\text { Signifikan } \\
\text { Tidak } \\
\text { Motivasi Kerja } \rightarrow \text { Kinerja Guru }\end{array}$ \\
\hline
\end{tabular}

Tabel 2 R-Squares Adjusted

\begin{tabular}{lcccccc}
\hline R-Squares Adjusted & $\begin{array}{c}\text { Original } \\
\text { Sample (O) Mean (M) }\end{array}$ & $\begin{array}{c}\text { Standard } \\
\text { Error } \\
\text { (STERR) }\end{array}$ & $\begin{array}{c}\text { T Statistics } \\
\text { (O/STERR) }\end{array}$ & P-Value & Keterangan \\
\hline Kinerja Guru & 0,005 & 0,085 & 0,056 & 0,084 & 0,933 & $\begin{array}{c}\text { Tidak } \\
\text { Signifikan }\end{array}$ \\
\hline
\end{tabular}

Tabel 2 memberikan gambaran bahwa variasi model yang bisa dijelaskan oleh konstruk kepemimpinan dan motivasi terhadap kinerja guru sangat marginal (hanya 0,50\%) dengan kondisi tidak signifikan, sehingga model yang didapat belum bisa dipergunakan untuk menjelaskan keterkaitan antar konstruk 
secara meyakinkan.

\section{Pengaruh Kepemimpinan Model Path Goal Terhadap Kinerja Guru}

Hipotesis 1, yang menyatakan semakin baik kepemimpinan path-goal dari kepala sekolah maka akan semakin meningkatkan kinerja guru. Dalam pengujian diperoleh bahwa kepemimpinan path-goal berpengaruh positif terhadap kinerja guru, dengan koefisien 0,251 serta dengan tstatistik sebesar 0,716 (atau t-statistik 0,716< 1,96), berarti hipotesis 1 tidak dapat diterima. Hasil temuan ini tidak sejalan dengan beberapa temuan yang didapat oleh Rachmawati (2013),Septiana, Ngadiman, and Ivada (2013), Arifin et al. (2014),Manik and Bustomi (2011), Ngiode (2016) , Purwoko (2018) yang mendapatkan terdapat pengaruh yang positif signifikan antara kepemimpinan kepala sekolah dengan kinerja guru. Nampaknya pendekatan model kepemimpinan path-goal dalam studi ini belum bisa memberikan dampak yang meyakinkan terhadap prestasi kerja guru Sekolah Dasar Negeri di Kecamatan Denpasar Barat Kodya Denpasar.

\section{Pengaruh Motivasi Kerja Terhadap Kinerja Guru}

Hipotesis 2, yang menyatakan semakin tinggi motivasi kerja maka akan semakin tinggi kinerja guru. Dalam pengujian hipotesis 2 , diperoleh bahwa motivasi kerja berpengaruh positif terhadap kinerja guru dengan nilai koefisien 0,085 serta p-statistik sebesar 0,233 (atau p-statistik $0,233<1,96)$,itu berarti hipotesis 2 tidak dapat diterima.Hal ini berarti sesuai dengan pernyataan bahwa semakin tinggi motivasi kerja maka akan semakin tinggi pula kinerja guru , akan tetapi dalam temuan ini belum bisa untuk digeneralisasi untuk populasi mengingat hasil yang didapat tidak signifikan. Hasil penelitian ini juga memperkuat temuan yang didapat oleh Sampurno and Wibowo (2017) yang menyatakan bahwa motivasi kerja tidak berpengaruh terhadap kinerja guru dan tenaga kependidikan. Hasil temuan ini tidak mendukung temuan yang didapat oleh Shahzadi et al. (2014),Astakoni (2015) yang menyatakan terdapat pengaruh positif signifikan antara motivasi kerja terhadap kinerja. Temuan ini juga tidak sejalan dengan hasil yang didapat Saragih and Yusfarita (2005),Mustafa and Othman (2010) ,Manik and Bustomi (2011) Septiana, Ngadiman, and Ivada (2013),Ngiode (2016) Zulkifli, Darmawan, and Sutrisno (2014),Sulistyawati, Fasochah, and Darsono (2016), Yunidar (2015), Djafar and Nurhafizah (2018), Abast et al. (2018),Susanto (2012), yang menjelaskan bahwa terdapat pengaruh positif signifikan antara motivasi kerja dengan kinerja guru.

\section{Pengujian Peran Gender Sebagai Group}

Sesuai dengan yang disajikan lewat Tabel 3 dan Tabel 4 dapat dijelaskan secara terpisah peran gender masing-masing melalui analisis multi-group.

Tabel 3: Path Coefficients Untuk Gender Laki-Laki

\begin{tabular}{lcccccc}
\hline \multicolumn{1}{c}{ Path Analysis } & $\begin{array}{c}\text { Original } \\
\text { Sample (O) Mean (M) }\end{array}$ & $\begin{array}{c}\text { Sample } \\
\text { Etror } \\
\text { (STERR) }\end{array}$ & $\begin{array}{c}\text { T Statistics } \\
\text { (O/STERR) }\end{array}$ & P-Value & Keterangan \\
\hline Kepemimpinan Path-Goal $\rightarrow$ Kinerja Guru & 0,103 & 0,104 & 0,326 & 0,316 & 0,752 & $\begin{array}{c}\text { Tidak } \\
\text { Signifikan } \\
\text { Tidak } \\
\text { Motivasi Kerja } \rightarrow \text { Kinerja Guru }\end{array}$ \\
& 0,217 & 0,220 & 0,291 & 0,747 & 0,455 & \begin{tabular}{c} 
Signifikan \\
\hline
\end{tabular} \\
\hline
\end{tabular}


Tabel 3 menjelaskan peran gender laki-laki sebagai determinan kinerja guru melalui variabel penentu kepemimpinan dan motivasi dengan arah yang positif . Pengaruh kepemimpinan terhadap kinerja guru sebesar 0,103 (positif) dan pengaruh motivasi terhadap kinerja guru sebesar 0,217 (positif) akan tetapi keduanya dengan kondisi tidak signifikan.

Tabel 4: Path Coefficients Untuk Gender Perempuan

\begin{tabular}{lcccccc}
\hline \multicolumn{1}{c}{ Path Analysis } & $\begin{array}{c}\text { Original } \\
\text { Sample (O) Mean (M) }\end{array}$ & $\begin{array}{c}\text { Sample } \\
\text { Error } \\
\text { (STERR) }\end{array}$ & $\begin{array}{c}\text { Standard } \\
\text { (O/STERR) }\end{array}$ & P-Value & Keterangan \\
\hline Kepemimpinan Path-Goal $\rightarrow$ Kinerja Guru & 0,430 & 0,257 & 0,493 & 0,872 & 0,384 & $\begin{array}{c}\text { Tidak } \\
\text { Signifikan } \\
\text { Tidak } \\
\text { Motivasi Kerja } \rightarrow \text { Kinerja Guru }\end{array}$ \\
\hline
\end{tabular}

Tabel 4 menjelaskan peran gender perempuan sebagai determinan kinerja guru melalui variabel penentu kepemimpinan dan motivasi dengan arah yang berbeda. Pengaruh kepemimpinan terhadap kinerja guru sebesar 0,430 (positif) dan pengaruh motivasi terhadap kinerja guru sebesar $-0,481$ (negatif) akan tetapi keduanya dengan kondisi tidak signifikan. Berdasarkan Tabel 3 dan 4 dapat dijelaskan peran gender perempuan melalui konstruk kepemimpinan terhadap kinerja guru lebih besar dari pada gender laki-laki . Sementara gender laki-laki melalui konstruk motivasi terhadap kinerja guru lebih besar dari pada gender perempuan.

\section{Simpulan}

Dalam pengujian hipotesis 1 , diperoleh bahwa kepemimpinan path-goal berpengaruh positif terhadap kinerja guru, dengan koefisien 0,097 serta t-statistik sebesar 0,364 (t-statistik 0,364<1,96) atau pvalue sebesar $0,176(>0,05)$, berarti hipotesis 1 tidak dapat diterima.

Dalam pengujian hipotesis 2 , diperoleh bahwa motivasi kerja berpengaruh positif terhadap kinerja guru dengan nilai koefisien 0,099 serta p-statistik sebesar 0,340 (p-statistik 0,340<1,96) atau p-value sebesar $0,734(>0,05)$, itu berarti hipotesis 2 tidak dapat diterima.

Peran gender perempuan melalui konstruk kepemimpinan terhadap kinerja guru lebih besar dari pada gender laki-laki . Sementara gender laki-laki melalui konstruk motivasi terhadap kinerja guru lebih besar dari pada gender perempuan.

\section{Implikasi}

Beberapa implikasi yang diharapkan dari hasil penelitian adalah sebagai berikut: Bahwa hasil penelitian ini dapat dipergunakan untuk menganalisis permasalahan kinerja guru khususnya lewat variabel kepemimpinan (kepala sekolah) dan motivasi kerja guru. Bahwa hasil penelitian ini dapat mendukung teori-teori manajemen sumber daya manusia, khususnya yang berkaitan dengan faktorfaktor yang mempengaruhi kinerja guru.

\section{Keterbatasan}

Peneliti hanya mengangkat 4 lembaga (Sekolah Dasar) sebagai sampel, sehingga hal ini tidak mampu menggambarkan keadaan secara umum (general). Peneliti pada beberapa kasus menitipkan 
kuesioner kepada pihak sekolah, karena tidak bisa bertemu secara langsung dengan responden pada saat pengisian kuesioner. Peneliti hanya mengangkat dua konstruk penenentu kinerja yaitu kepemimpinan dan motivasi mengingat konstruk lain masih sangat banyak.

Saran

Upaya untuk meningkatkan motivasi kerja guru diperlukan melalui pemenuhan kebutuhan sosial, penghargaan dan aktualisasi diri, sehingga guru yang telah terpenuhi kebutuhannya, diharapkan akan bekerja dengan baik. Dalam meningkatkan kinerja guru, perlu untuk meningkatkan motivasi melalui sikap dan perilaku guru yang baik dalam membangun nilai dan norma di sekolah. Lewat nilai-nilai dan norma yang baik diterapkan bersama, para guru akan menunjukkan kinerja yang baik dalam mencapai tujuan yang ditetapkan.

\section{Daftar Pustaka}

Abast, R. M., N. M. Sangi, M. S.S.S. Tumanduk, and R. Roring. 2018. Motivation, Compensation, and Performance for Science and Technological Teachers. IOP Conference Series: Materials Science and Engineering 306 (1).1-11,

Arifin, Freddy, Eka Afnan Troena, Djumahir, and Mintarti Rahayu. 2014. Organizational

Culture , Transformational Leadership, Work Engagement, and Teacher Performance :Test of a

Model. International Journal of Education And Research 2 (1): 1-14.

Astakoni, Purba I Made. 2015. Pengaruh Motivasi, Iklim Organisasi Dan Gaya Kepemimpinan Terhadap Kinerja Karyawan (Studi Pada Koperasi Asadana Semesta, Denpasar). Jurnal Forum Manajemen 13 (2): 25-33.

Cokquitt, Jasson A., and A LePine. 2009. Organizational Behavior Improving Performance and Commitment in the Workplace. Boston: McGraw-Hill-Irwin.

Dessler, G. 2005. Human Resource Management. 10thed. India: Pearson Prentice Hall.

Djafar, Hamsiah, and Nurhafizah . 2018. Pengaruh Motivasi Kepala Sekolah Terhadap Kinerja Guru Dan Pegawai Di SMK Muhammadiyah 3 Makassar. Idaarah: Jurnal Manajemen Pendidikan 2 (1): 24-36.

Hatifah, R. D. 2015. Pengaruh Relasi Gender Dan Pengambilan Keputusan Terhadap Kinerja Guru Sekolah Menengah Pertama Negeri (SMP Negeri) Di Kecamatan Bekasi Selatan Kota Bekasi. Jurnal Manajemen Pendidikan, 6(2), 1097-1107.

Hasibuan, Malayu S.P. 2007. Organisasi Dan Motivasi. Jakarta: Bumi Aksara.

House, Robert J, and Terence R. Mitchell. 1975. Path Goal Theory Of Leadership. Washington: National Technical Information Serices US Departemen Of Commerce.

Inayatullah, Atiya, and Palwasha Jehangir. 2012. Teacher's Job Performance: The Role of Motivation. Abasyn Journal of Social Sciences 5 (2): 78-99.

Indrafachrudi, Soekarta. 2006. Bagaimana Memimpin Sekolah Yang Efektif. Bogor: PT. Ghalia Indonesia.

Khoir, Dhany Hamiddan. 2012. Faktor-Faktor Yang Mempengaruhi Kinerja Pegawai Pada Direktorat Pembinaan Sekolah Dasar Ditjen Pendidikan Dasar Kemdikbud. Jakarta: (Skripsi) Universitas Indonesia.

Ma'Ruf. 2014. Pengaruh Gaya Kepemimpinan Terhadap Kepuasan Kerja Model Path Goal ( Studi Empiris Pada Lembaga Pendidikan Perguruan Tinggi Swasta Di Surakarta ). In Seminar Nasional Dan Call For Paper,408-417. Fakultas Ekonomi dan Bisnis Universitas Muhammadiah Surakarta.

Mangkunegara, AA Anwar Perabu. 2010. Evaluasi Kinerja SDM. Bandung: Refika Aditama.

Manik, Ester, and Kamal Bustomi. 2011. Pengaruh Kepemimpinan Kepala Sekolah, Budaya Organisasi Dan Motivasi Kerja Terhadap Kinerja Guru Pada SMP Negeri 3 Rancaekek Jurnal Ekonomi,Bisnis \& Enterpreneurship 5 (2): 97-107. 
Mulyasa, E. 2004. Menjadi Kepala Sekolah Profesional. Bandung: PT Remaja Rosdakarya. 2005. Manajemen Berbasis Sekolah. Bandung: PT Remaja Rosdakarya.

Mustafa, M.Nur, and Norasmah Othman. 2010. The Effect of Work Motivation on Teacher'S Work Performance in Pekanbaru Senior High Schools, Riau Province, Indonesia. Sosiohumanika $3(2)$ :

$259-272$.

Ngiode, Syafrin. 2016. Pengaruh Kepemimpinan Kepala Sekolah, Motivasi Kerja Dan Disiplin Kerja Terhadap Kinerja Guru MTs . N Batudaa Kabupaten Gorontalo. Tadbir, Jurnal Manajemen Pendidikan Islam 4 (2): 127-137.

Pidarta, Made. 2004. Manajemen Pendidikan Indonesia. Jakarta: Rineka Cipta.

Purwoko, Sidik. 2018. Pengaruh Kepemimpinan Kepala Sekolah,Komitmen Guru,Disiplin Kerja Guru Dan Budaya Sekolah Terhadap Kinerja Guru SMK. Jurnal Akuntabilitas Manajemen Pendidikan 6 (2): 149-162.

Rachmawati, Yulia. 2013. Pengaruh Kepemimpinan Kepala Sekolah Terhadap Kinerja Guru. Jurnal Pendidikan Ekonomi IKIP Veteran Semarang 1 (1): 19-28.

Rasool, Humayun Faiz, Irfan Ullah Arfeen, Wahbeeah Mothi, and Usman Aslam. 2015. Leadership Styles and Its Impact on Employee's Performance in Health Sector of Pakistan. City University Research Journal 5 (1): 97-109.

Robbins, Stephen, and Timothy Judge. 2009. Organization Behavior. New Jersey: Pearson Education Inc.

Robbins, Stephen P. 2008. Organizational Behavior. Ten Editio. New Jersey: Prentice Hall,Inc.

Sampurno, Dwi, and Agus Wibowo. 2017. Kepemimpinan Kepala Sekolah, Lingkungan Kerja, Motivasi Kerja, Dan Kinerja Guru Di SMK Negeri 4 Pandeglang. Jurnal Pendidikan Ekonomi Dan Bisnis (JPEB) 3 (2): 63-76.

Saragih, Muhammad Rizal, and Yusfarita. 2005. Pengaruh Budaya Organisasi, Kompetensi Guru Dan Motivasi Terhadap Kinerja Guru SDN Joglo 05 Pagi Jakarta. Inovasi,Jurnal Ilmiah Ilmu Manajemen E-ISSN 2598-4950, 45-59.

Septiana, Roslena, Ngadiman, and Elvia Ivada. 2013. Pengaruh Kepemimpinan Kepala Sekolah Dan Motivasi Kerja Terhadap Kinerja Guru SMP Negeri Wonosari. Jupe UNS 2 (1): 107-118.

Shahzadi, Irum, Ayesha Javed, SyedShahzaib Pirzada, and Shagufta Nasreen. 2014. Impact of Motivation on Employee Performance. International Journal of Business and Management 6 (23): 159-166.

Sulistyawati, Nanik, Fasochah, and Darsono. 2016. Pengaruh Profesional Dan Motivasi Kerja Terhadap Kinerja Guru Dengan Lingkungan Kerja Sebagai Variabel Moderasi ( Studi Pada SMP Negeri Se Kecamatan Boja Kabupaten Kendal ). Jurnal Dharma Ekonomi, no. 43: 44-52.

Susanto, Hary. 2012. Faktor-Faktor Yang Mempengaruhi Kinerja Guru Sekolah Menengah Kejuruan." Jurnal Pendidikan Vokasi 2 (2): 197-212.

Timpe, A. Dale. 2002. Seri Manajemen Sumber Daya Manusia: Kepemimpinan, Alihbahasa: Susanto Budhidarmo. Jakarta: PT Gramedia Pustaka Utama.

Triwahyuni, Lulus, Abdullah Thamrin, and Sunaryo Widodo. 2014. The Effect of Organizational Culture, Transformational Leadership and Self-Confidence to Teachers' Performance. International Journal of Managerial Studies and Research 2 (10): 156165.

Yunidar. 2015. Pengaruh Budaya Organisasi Dan Motivasi Kerja Terhadap Kinerja Guru Pada SD Negeri Di Kecamatan Rimbo Tengah Kabupaten Bungo (Tesis). Universitas Terbuka.

Zulkifli, Mohammad, Arif Darmawan, and Edy Sutrisno. 2014. Motivasi Kerja, Sertifikasi, Kesejahteraan Dan Kinerja Guru. Persona: Jurnal Psikologi Indonesia 3 (2): 148-155. 